\title{
Retinal venous pressure in the non-affected eye of patients with retinal vein occlusions
}

\author{
Maneli Mozaffarieh • M. Bärtschi • P. B. Henrich • \\ A. Schoetzau • J. Flammer
}

Received: 3 December 2013 / Revised: 6 March 2014 / Accepted: 10 March 2014 / Published online: 28 March 2014

(C) Springer-Verlag Berlin Heidelberg 2014

\begin{abstract}
Background To measure the retinal venous pressure (RVP) in both eyes of patients with unilateral central retinal vein occlusions and to compare these values to controls.

Methods The study included 31 patients with unilateral central retinal vein occlusions (CRVO) and 31 controls who were matched by age, sex, and systemic disease. RVP was measured in all patients bilaterally by means of contact lens ophthalmodynamometry, and the RVP measurements of the affected and unaffected eyes of patients were compared to the RVPs of controls. Ophthalmodynamometry is done by applying an increasing pressure on the eye via a contact lens. The minimum force required to induce a venous pulsation is called ophthalmodynamometric force (ODF). The RVP is defined and calculated as the sum of ODF and intraocular pressure (IOP) $[\mathrm{RVP}=\mathrm{ODF}+\mathrm{IOP}]$.

Results The RVP group means \pm SD were as follows: patient's affected eyes $(45.0 \pm 11.6 \mathrm{mmHg})$, patient's unaffected eyes $(38.0 \pm 11.1 \mathrm{mmHg})$, and $(17.7 \pm 6.7 \mathrm{mmHg})$ in the eyes of controls. The values of RVP, even in the patients unaffected eyes, were significantly higher than in the eyes of controls $(P$ $<0.001)$.

Conclusions In patients with CRVO, the RVP is increased in both the affected as well as in the unaffected contralateral eye.
\end{abstract}

Keywords Retinal venous pressure $\cdot$ Central retinal vein occlusion $\cdot$ Unaffected contralateral eye

M. Mozaffarieh $(\triangle) \cdot$ M. Bärtschi • P. B. Henrich • A. Schoetzau • J. Flammer

Department of Ophthalmology, University of Basel, Mittlere Strasse 91, 4031 Basel, Switzerland

e-mail: Maneli.Mozaffarieh@usb.ch

\section{Introduction}

A retinal vein occlusion (RVO) is a sight-threatening disease. It can be divided into central retinal vein occlusion (CRVO) and a branch retinal vein occlusion (BRVO). Although different aetiological factors [1-4] and therapeutic approaches [5-10] have been proposed, the pathogenesis of the condition still remains debatable [11-13]. In this context, ophthalmodynamometric measurements of retinal venous pressure (RVP) in eyes of patients with retinal vein occlusions is of special interest.

Knowledge about the RVP of the unaffected eyes of patients with a CRVO gives hints about the possibility of systemic factors being involved in the pathogenesis of the disease. For this reason, we performed this study and measured RVP in both the affected and unaffected eyes of patients with a CRVO. As expected, patients with a CRVO have a higher RVP in their affected eyes [14]. To the best of our knowledge, however, we report for the first time a significantly increased RVP in the non-affected contralateral eyes of such patients.

\section{Methods}

Thirty-one patients with a unilateral CRVO (seven ischemic and 24 non-ischemic) and 31 age- and sex-matched volunteers were included in the study between January 2011 and September 2012. Patients were recruited from the University Eye Clinic Basel; the control subjects, who were matched by age, sex, refractive-error, and systemic disease were recruited in our outpatient department. Control subjects did not have any relevant eye disease. Ethical approval was obtained from the local medical ethics committee before entering into the study. The study was designed and conducted in accordance with the tenets of the Declaration of Helsinki. Included were patients with a unilateral CRVO, confirmed with fundus 
photography as well as fluorescein angiography. There were no exclusion criteria. At the initial work-up, all patients received a comprehensive ophthalmic examination followed by fundus photography and fluorescence angiography of the retina. A blood test was done in all patients including full blood count and lipid profiles as well as measurement of blood coagulation factors.

For all patients and controls, RVP was measured in both eyes by ophthalmodynamometry (Meditron $\mathrm{GmbH}$, Völklingen, Germany). This device consists of a conventional Goldmann contact lens fitted with a pressure sensor (at its outer margin where the Goldmann contact lens is usually held during an ophthalmoscopic examination) connected to an LCD screen.

Ophthalmodynamometry is done by applying an increasing pressure on the eye via the contact lens. This applied pressure can be read as an IOP increase on the attached LCD screen based on a calibration curve. The calibration of the conversion of the applied force to $\Delta \mathrm{P}$ has been shown by Morgan et al., who found that the correlation between induced IOP and ODF is strong and the relationship is linear [15]. The IOP increase required to induce a venous pulsation is called the ophthalmodynamometric force (ODF). If a spontaneous venous pulsation is present, ODF is said to be 0 ; if not, increasing pressure is applied. The RVP is defined and calculated as the sum of the ODF and IOP [RVP $=$ ODF + IOP $]$.

\section{Statistical analysis}

A linear mixed effects model was performed to compare values of the RVP of the eyes with a CRVO to the contralateral unaffected eye and to the eyes of controls. The independent factor is "Status" (affected and unaffected eyes of patients and eyes of controls); the dependent variable was the RVP. The subject was treated as a random factor. To adjust for a potential influence of the IOP, these factors were also included in the model. Adjustment means that results are presented at a fixed IOP value. The results are presented in Table 1 as means \pm SD. In addition, the differences with their $95 \%$ confidence intervals (CI) are reported. A $P$-value $<0.05$ was considered significant.

\section{Results}

Table 1 depicts the values in mean and standard deviation (in brackets) for IOP and RVP in both eyes of patients with unilateral CRVO as well as in the controls. Eleven of the controls had a spontaneous venous pulsation in both eyes.Table 2 gives an overview of the demographic data of patients and controls.

No significant differences were detected in the IOP of the eyes of patients with a CRVO in comparison to controls. RVP
Table 1 Descriptive statistics: age, gender, and concomitant diseases in the two groups

\begin{tabular}{lll}
\hline & Patients & Controls \\
\hline$N$ & 31 & 31 \\
Age & $62.8 \pm 14.7$ & $62.6 \pm 13.8$ \\
Gender & & \\
$\quad$ Female & 15 & 14 \\
$\quad$ Male & 16 & 17 \\
Concomitant diseases & & \\
$\quad$ Arterial hypertension \& hyperlipidaemia & 5 & 8 \\
Arterial hypertension & 6 & 2 \\
$\quad$ Hyperlipidaemia & 5 & 0 \\
$\quad$ Diabetes mellitus type 2 & 3 & 3 \\
Primary vascular dysregulation (PVD) [12] & 6 & 4 \\
PVD \& hypothyroidism & 0 & 1 \\
Hypothyroidism & 2 & 0 \\
Depressive disorder & 1 & 0 \\
\hline
\end{tabular}

was $20.3 \mathrm{mmHg}$ higher in the patients' unaffected contralateral eyes in comparison to eyes of controls [confidence interval (CI): 15.7 to $24.9 ; P<0.001]$. When adjusted for IOP, RVP was $17.7 \mathrm{mmHg}$ higher in the patients' unaffected contralateral eyes in comparison to eyes of controls [confidence interval (CI): 13.3 to $22.1 ; P<0.001]$. RVP was $7 \mathrm{mmHg}$ higher in the patients' CRVO-affected eyes in comparison to their unaffected 'healthy' eyes [confidence interval (CI): 4.7 to 9.4; $P<0.001]$. When adjusted for IOP, RVP was $6.9 \mathrm{mmHg}$ higher in the patients' CRVO-affected eyes in comparison to their unaffected 'healthy' eyes [confidence interval (CI): 4.6 to 9.2; $P<0.001]$.

\section{Discussion}

An increased RVP in eyes of patients with CRVO has already been reported $[14,16]$ and this increase was significantly higher in the ischemic than in the non-ischemic group [16]. To the best of our knowledge, this is the first report of an

Table 2 IOP and RVP measurements. Mean and SD values for IOP and RVP in the affected and unaffected eyes of patients as well as in both eyes of controls

\begin{tabular}{llllll}
\hline & \multicolumn{2}{l}{ Patients } & & & Controls \\
\cline { 2 - 3 } \cline { 5 - 6 } & $\begin{array}{l}\text { Affected } \\
\text { eye }\end{array}$ & $\begin{array}{l}\text { Unaffected } \\
\text { eye }\end{array}$ & & Right eye & Left eye \\
& 31 & 31 & 31 & 31 \\
\hline Number of eyes & 31 & $16.6(3.96)$ & $13.6(3.84)$ & $13.8(3.86)$ \\
IOP: mean, (SD) & $16.4(3.93)$ & & \\
RVP: mean, (SD) & $45.0(11.6)$ & $38.0(11.1)$ & & $16.3(7.5)$ & $17.3(6.7)$ \\
\hline
\end{tabular}

$I O P$ Intraocular pressure, $R V P$ Retinal venous pressure 
increased RVP in the patient's unaffected contralateral eyes which is statistically significant and, from our point of view, also clinically relevant.

At present, the cause of this increase is not known and needs to be clarified by other studies. There are two potential explanations: (a) the underlying eye disease affects both eyes of such patients but becomes clinically manifest only in the more severe affected eye, or (b) the RVP increase is due to systemic factors such as increased level of endothelin-1, as has been found in vascular occlusive diseases [17, 18]. The endothelin-1 can either come from the circulating blood [19] where it can diffuse through the fenestrated capillaries of the choroid to the optic nerve head (not fully protected by a barrier), or it can be produced by the atherosclerotic altered arteries [20], and finally it can also be produced locally along with other molecules such as VEGF by hypoxic tissues [21].

In conclusion, our results raise the question, whether a venous thrombus is indeed the primary cause of RVO. These results rather support the assumption that a functional constriction of the vein may be involved [11-13].

Conflict of interest Mozaffarieh M, Henrich PB and Schoetzau A have no conflict of interest.

Baertschi $\mathrm{M}$ and Flammer $\mathrm{J}$ are the co-owners of the patent for the ophthalmodynamometer.

\section{References}

1. Napal Lecumberri JJ, Sedano Balbas C, Canal Villanueva J, Hernandez Hernandez JL (2013) Thrombophilia and vascular risk factors in retinal vein occlusion. Rev Clin Esp 213(5):229-234 (article in English/Spanish)

2. Zhou JQ, Xu L, Wang S, Wang YX, You QS, Tu Y et al (2013) The 10 -year incidence and risk factors of retinal vein occlusion: the Beijing Eye Study. Ophthalmology 120(4):803-808

3. Lee JY, Yoon YH, Kim HK, Yoon HS, Kang SW, Kim JG et al (2013) Baseline characteristics and risk factors of retinal vein occlusion: a study by the Korean RVO Study Group. J Korean Med Sci 28(1): 136-144

4. Giannaki K, Politou M, Rouvas A, Merkouri E, Travlou A, Theodosiadis P et al (2013) Retinal vein occlusion: genetic predisposition and systemic risk factors. Blood Coagul Fibrinolysis 24(3): 279-283

5. McAllister IL, Vijayasekaran S, Yu DY (2013) Intravitreal Tenecteplase (metalyse) (TNK) for acute management of retinal vein occlusions. Invest Ophthalmol Vis Sci 54(7):4910-4918
6. Kadonosono K, Yamane S, Arakawa A, Inoue M, Yamakawa T, Uchio E et al (2013) Endovascular cannulation with a microneedle for central retinal vein occlusion. JAMA Ophthalmol 131(6):783786

7. Matonti F, Meyer F, Guigou S, Barthelemy T, Dumas S, Gobert F et al (2013) Ozurdex in the management of the macular edema following retinal vein occlusion in clinical practice. Acta Ophthalmol 91(7):e584-e586

8. Lu Y, Su L, Xu X (2013) Bevacizumab for macular edema secondary to retinal vein occlusion: a systematic review and meta-analysis. $\mathrm{J}$ Ocul Pharmacol Ther 29(8):702-708

9. Huang P, Niu W, Ni Z, Wang R, Sun X (2013) A metaanalysis of anti-vascular endothelial growth factor remedy for macular edema secondary to central retinal vein occlusion. PLoS One 8(12):e82454

10. Rehak M, Tilgner E, Franke A, Rauscher FG, Brosteanu O, Wiedemann P (2013) Early peripheral laser photocoagulation of nonperfused retina improves vision in patients with central retinal vein occlusion (Results of a proof of concept study). Graefes Arch Clin Exp Ophthalmol [Epub ahead of print]

11. Fraenkl SA, Mozaffarieh M, Flammer J (2010) Retinal vein occlusions: the potential impact of a dysregulation of the retinal veins. EPMA J 1(2):253-261

12. Flammer J, Konieczka K, Flammer AJ (2013) The primary vascular dysregulation syndrome: implications for eye diseases. EPMA J 4(1): 14

13. Flammer J, Konieczka K, Bruno RM, Virdis A, Flammer AJ, Taddei S (2013) The eye and the heart. Eur Heart J 34(17):1270-1278

14. Jonas JB (2003) Ophthalmodynamometric assessment of the central retinal vein collapse pressure in eyes with retinal vein stasis or occlusion. Graefes Arch Clin Exp Ophthalmol 241(5):367-370

15. Morgan WH, Cringle SJ, Kang MH, Pandav S, Balaratnasingam C, Ezekial D et al (2010) Optimizing the calibration and interpretation of dynamic ocular force measurements. Graefes Arch Clin Exp Ophthalmol 248(3):401-407

16. Jonas JB, Harder B (2007) Ophthalmodynamometric differences between ischemic vs nonischemic retinal vein occlusion. Am J Ophthalmol 143(1):112-116

17. Haufschild T, Prunte C, Messerli J, Flammer J (2004) Increased endothelin-1 plasma level in young adults with retinal vascular occlusive diseases. Klin Monatsbl Augenheilkd 221(5):357-359

18. Iannaccone A, Letizia C, Pazzaglia S, Vingolo EM, Clemente G, Pannarale MR (1998) Plasma endothelin-1 concentrations in patients with retinal vein occlusions. Br J Ophthalmol 82(5):498-503

19. Faraco G, Moraga A, Moore J, Anrather J, Pickel VM, Iadecola C (2013) Circulating endothelin-1 alters critical mechanisms regulating cerebral microcirculation. Hypertension 62(4):759-766

20. Tsui JC, Shi-Wen X (2011) Endothelin-1 in peripheral arterial disease: a potential role in muscle damage. Pharmacol Res 63(6):473476

21. Friedman JK, Nitta CH, Henderson KM, Codianni SJ, Sanchez L, Ramiro-Diaz JM et al (2014) Intermittent hypoxia-induced increases in reactive oxygen species activate NFATc3 increasing endothelin-1 vasoconstrictor reactivity. Vasc Pharmacol 60(1):17-24 